\title{
PIVOT FOR THE PANDEMIC: COMPARISON OF TOY AND SCIENCE DEMo DeSIGN ProJeCTS IN A First YeAR MECHANICAL ENGINEERING COURSE
}

\author{
Andrew J B Milne, Roydon Fraser, J Baleshta, and Michael Collins \\ University of Waterloo Mechanical and Mechatronics Engineering Department \\ ajbmilne@uwaterloo.ca
}

\begin{abstract}
The first year course, "ME 100: Introduction to Mechanical Engineering Practice, 1", was redesigned for the Fall 2017-2019 offerings. The goals of the redesign were to include: a major design project, opportunities for individual communication assessments, and opportunities for development of professional skills. A toy design project was piloted in Fall 2017 as a unifying course theme. In this project, industrial partners come to discuss the engineering and design that happens in the toy industry. They also help critique student work as they design a toy of their choosing. With the impacts of COVID 19 the decision was made to pivot to a challenge to design new classroom physics demonstrations. The course redesign has generally been successful. Both projects have been well received by students, faculty, and industry partners, with students reporting on an end-of-term survey that it was engaging and doable, and that it helped develop their confidence and understanding of design, and mechanical engineering. The demo project was generally slightly better received, with $2-8 \%$ more students agreeing to statements about the usefulness and appeal of the project. Both projects, the toy project especially, serve as a vehicle to discuss different aspects of design and professionalism. Challenges exist with giving students guidance at the start and throughout the project to ensure that all student teams have suitably scoped projects. There is also the challenge of helping students develop a design mindset, as several groups struggle with performing the justified decision making necessary to actual design a toy.
\end{abstract}

Keywords: Design, Design Course, Industry Partner, Authentic Assessment, Mechanical Engineering, First Year Course

\section{INTRODUCTION}

As a first term, first year course, ME 100: Introduction to Mechanical Engineering Practice 1 at the University of Waterloo (UW) has a large scope which is partially captured by its course description. As the course title/description suggests, ME 100 must introduce students to what it means to be a practicing mechanical engineer in Canada. As the only ME course in the term, it must feel to students like an engineering course, rather than solely a communication ('English') or professionalism course. The goal is to make students feel like they are doing 'engineering work' while they are learning about professionalism and communication.

For decades, the course has had two parts, which are currently called Engineering Graphics and Design (EGAD) and Design, Communication, and Professionalism (DCAP). EGAD provides design instruction and practical industrial knowledge along with hands on training in AutoCAD, SolidWorks, and hand sketching. It is focussed on individually completed weekly assessments. DCAP also provides design instruction, providing opportunity for multi-week team design projects which necessitate the inclusion of communication and professionalism aspects such as team meetings, teamwork, reports, and consideration of safety and risks. This second part of the course is the focus of this paper.

As context, this is a large design course (being offered to $210-250$ students divided between two sections, with 9 contact hours a week for each of the sections, including 3 hours per week of EGAD instruction). The size of the course impacts both the design of course and the required resources. With $\sim 50-60$ project groups, any design project focussed on a single challenge is prone to groups converging on each other's solutions. Given the size, the course is supported by two teaching tasks per section, 5 full time (40 hour per week) Undergraduate TA's, and parttime support from full-time senior tutors (permanent employees of the University). Additional human and physical resources have been brought to bear for the design project as described in Section 2.

The lead author, AJBM began teaching this course in Fall 2017 with MRC as a co-instructor. The lead author has taught the course since with RAF. JB teaches EGAD. 


\section{Course Redesign, PhILOSOPHY, AND EFFECTS OF COVID-19}

In preparation for first co-offering the course in Fall 2017, the lead author used the Spring 2017 term to redesign the course. Based on an analysis of the learning objectives of the course within the broader Mechanical Engineering program, the goals of the redesign were to include: a major design project, opportunities for individual communication assessments, and opportunities for development of professional skills. Authenticity of all assessments was prioritized, which led to the difficult question of picking a design challenge that would involve authentic engineering design tasks (problem analysis, ideation, and analysis/fabrication/testing) but still be relatable to students (a context that is familiar enough to them), and scoped to be something they can understand, analyze, and complete with their basically secondary school knowledge [1]. As stated in Section 1, the choice was made that the project had to be one in which student groups picked their own topic within a general scope, in order to decrease the likelihood of students shortcutting the design process by converging on each other's solutions.

It was decided that a toy design project satisfied the course requirements. The field of toy design is large (permitting students to pick distinct topics/challenges). The challenge is relatable in that all students should have knowledge of toys, (nearly) all students have experience playing with toys, and many students have recent experience playing with toys. The scale of the challenge (something human sized, with low to medium complexity) also meant that the challenge could be scoped to the time and abilities of $1 \mathrm{~A}$ students. The idea for the project was inspired by the MIT 2.00b course on Toy Product Design taught by Dr. David Wallace and Josh Ramos [2].

To lend greater authenticity to the project, the teaching team partnered with Spin Master (a toy company headquartered in Toronto). Spin Master graciously provided a kickoff lecture on design, a middle of project design review, and an end of term visit to the symposium for final comments. Based on their suggestion, individual project groups were also assigned specific age ranges and play patterns (construction, craft, role play, collectible, etc) in order to decrease the likelihood of one group copying a toy idea from another.

In order to support this project and its related design, communication, and professionalism objectives, the weekly schedule of lectures and milestones was scheduled as given in Table 1(next page). Table 1 also shows the rationale behind each item. This schedule bears similarities to that employed in the Mechatronics 1A term for their Lego Robot design project [3], since the organizers of that course were gracious enough to share their planning and reasoning with the authors.

With the impacts of COVID 19 (including remote learning and students having an incomplete learning a physics) the decision was made in Summer 2020 to pivot to a project where student designed new classroom or athome physics demonstrations. This choice was deliberately made to:

1) Encourage students to review their high school physics/other concepts as they applied them to the project

2) Acknowledge that we are all learning from home and that high school and other instructors need demonstrations all the time, and that at home demonstrations are especially lacking

3) Give value to the fact that all student would have to attempt prototyping at home using available materials. Whereas for the toy project we expected this would result in multiple copies of less polished toys, in the case of demonstrations we encouraged students to approach it as a test of the buildability and robustness of their designs to fluctuations in what was available

Aside from the change in projects, the structure of the course and project were otherwise similar from 2017 to 2020. A comparison of the 2017 and 2020 activities and rationale is also given in Table 1. The three largest changes (aside from the topic of the project were: 1) a choice to spend the first week's session meeting with students in groups of four, 2) the introduction of a small project to design, build, and test a dynamometer to calculate the torque-speed curve of a $5 \mathrm{~V}$ hobby-style geared motor, and 3 ) starting the main design project one week earlier (based on student requests from previous years) and running mini check-ins each week during the project between each group and their TA. All changes were well received. The first helped to make students feel connected to the teaching team immediately, which was deemed extremely important in the online environment. The second was well received by students who commented on it being an excellent learning activity and preparation for the main design project. Regarding the third, we found that the weekly check-ins helped ensure that students were not floundering with their project in the online/remote environment. Students continued to ask for the main project to start even earlier in the next course offering, based upon the results of the end-of-term survey as described next. 
Table 1: An approximate weekly outline of course activities related to the main design projects in ME 100 at the University of Waterloo.

\begin{tabular}{|c|c|c|c|}
\hline Week & 2017-2019 Activity & 2020 Activity & Rationale \\
\hline $\begin{array}{l}1 \\
\text { (Partial } \\
\text { Week) }\end{array}$ & 1-2 hour paper rocket design & $\begin{array}{l}\text { Small group meeting with } \\
\text { Professors }\end{array}$ & $\begin{array}{l}\text { Immediate and accessibly design activity to form connection } \\
\text { with classmates (2017-2019) vs equipment check and } \\
\text { activity to form connection with professors }\end{array}$ \\
\hline $2-4$ & $\begin{array}{l}\text { Various small (non-design) } \\
\text { activities }\end{array}$ & $\begin{array}{l}\text { Design, build, and test a } \\
\text { mechanical dynamometer } \\
\text { using materials at home and a } \\
5 \mathrm{~V} \text { hobby motor }\end{array}$ & $\begin{array}{l}\text { Introduce students to each other, varying groups with each } \\
\text { activity within a } \sim 25 \text { person tutorial section vs doing the } \\
\text { same while introducing fundamental concepts of electric } \\
\text { motors and the design process }\end{array}$ \\
\hline 4 & Kickoff visit from Spin Master & $\begin{array}{l}\text { Introduction of project by } \\
\text { professors with an industry } \\
\text { talk by Spin Master later }\end{array}$ & Motivate students with industrial relevance. \\
\hline 5 & $\begin{array}{l}\text { Prototyping lecture (offered } \\
\text { by WatlMake maker space) } \\
\text { and toy dissection }\end{array}$ & Demo project ideation & $\begin{array}{l}\text { Explain prototyping tools available and emphasize } \\
\text { philosophy of low order works-like prototyping vs getting } \\
\text { and earlier start on the main project based on student } \\
\text { feedback. See row below for explanation of ideation } \\
\text { rationale }\end{array}$ \\
\hline 6 & Toy Ideation & Reading week & $\begin{array}{l}\text { Focus on generation of tens of ideas to develop }>2 \text { viable } \\
\text { ideas }\end{array}$ \\
\hline 7 & Midterm break & $\begin{array}{l}\text { Continue to work on } \\
\text { proposals/ideation }\end{array}$ & 1 week without lectures/activities \\
\hline 8 & Toy Proposal & Demo Proposal & Critique of two potential ideas by TAs \\
\hline 9 & $\begin{array}{l}\text { Free work time or other } \\
\text { activities }\end{array}$ & $\begin{array}{l}\text { Project work time with } \\
\text { schedule check-in with TA }\end{array}$ & $\begin{array}{l}\text { Modification in } 2020 \text { to include weekly check-ins was based } \\
\text { on experience of previous years that some groups } \\
\text { suffered/floundered in silence }\end{array}$ \\
\hline 10 & Midterm Design Review & Midterm Design Review & $\begin{array}{l}\text { Ensure students are making progress/have begun } \\
\text { prototyping, critiques by TAs, Faculty volunteers, and Spin } \\
\text { Master (Spin Master not involved in 2020) }\end{array}$ \\
\hline 11 & $\begin{array}{l}\text { Free work time or other } \\
\text { activities }\end{array}$ & $\begin{array}{l}\text { Project work time with } \\
\text { schedule check-in with TA }\end{array}$ & $\begin{array}{l}\text { Modification in } 2020 \text { to include weekly check-ins was based } \\
\text { on experience of previous years that some groups } \\
\text { suffered/floundered in silence }\end{array}$ \\
\hline 12 & Symposium, Draft Report & $\begin{array}{l}\text { Presentation to tutorial } \\
\text { section, Draft Report }\end{array}$ & $\begin{array}{l}\text { Ensure students have (mostly) finished their design work, } \\
\text { and started their reports weeks before final exams }\end{array}$ \\
\hline 13 & Report Feedback & Report Feedback & Give constructive feedback on reports/design \\
\hline 14 & $\begin{array}{l}\text { Farewell Lecture (Partial } \\
\text { Week) }\end{array}$ & $\begin{array}{l}\text { Farewell Lecture } \quad \text { (Partial } \\
\text { Week) }\end{array}$ & Celebrate accomplishments of students, collect reports \\
\hline
\end{tabular}

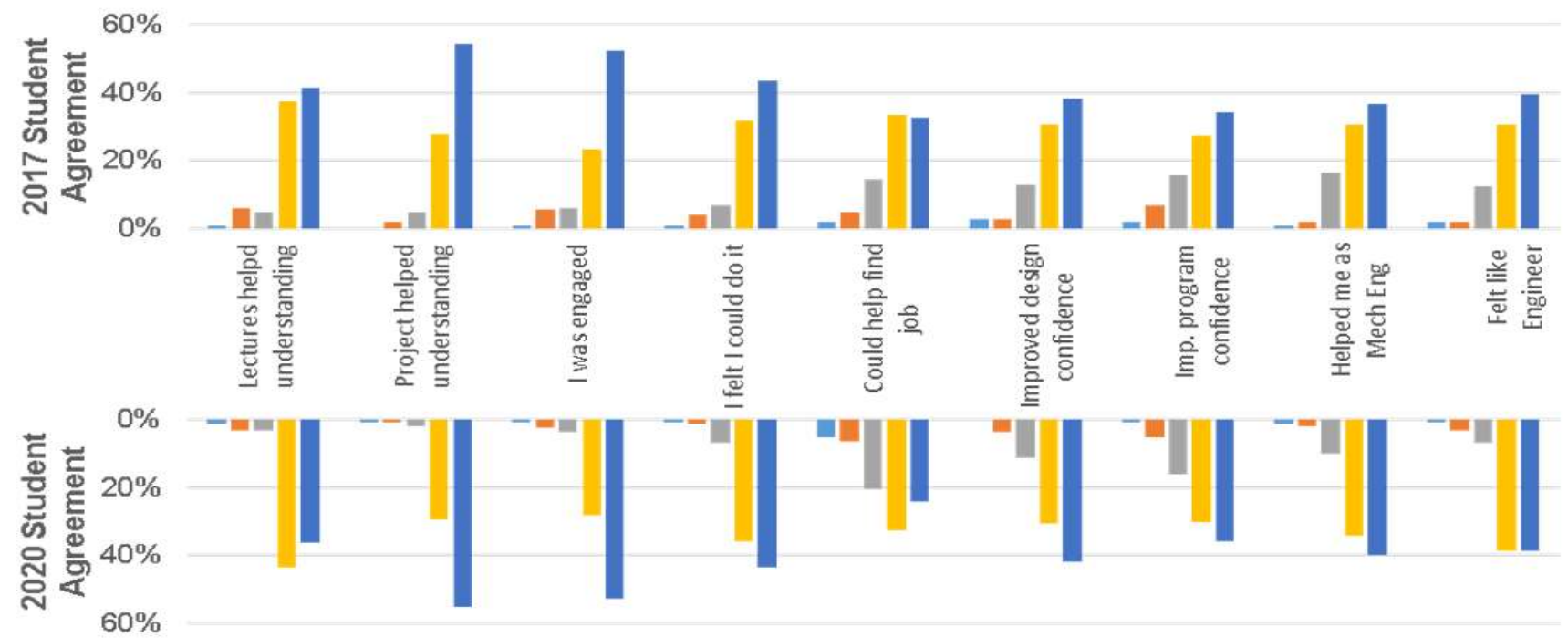

mStrongly disagree = Somewhat disagree $=$ Neither agree nor disagree $=$ Somewhat agree $=$ Strongly agree

Figure 1: Comparison of student responses to end-of-term survey questions. Top is data from 2017, bottom is data from 2020. 


\section{RESUlTS AND DisCUSSION}

Student perceptions of various aspects of the course, including the main design project, were probed in 2017 and 2020 via an end-of-term (EOT) survey developed and administered using the Qualtrics platform. Student participation in the survey was incentivised by a $1 \%$ bonus mark, but it was made clear to students that they could obtain this mark without including any information in the survey. Survey responses were taken by an arms-length staff person uninvolved in the course/grading, who provided a list after classes were over of students who should receive the bonus mark. This same staff person then anonymized the raw data after grades were submitted for the term, and before sharing the results with the authors. Using this technique, the survey response rate was $60 \%$ in 2017 and $80 \%$ in 2020 . We were somewhat surprised by the increase in response rate. It is possible that the impacts of the pandemic and the resulted efforts we made resulted in a better connection with students. It is also possible they felt more inclined to provide feedback given the recognition that the remote/online term was different and new, and would benefit from the feedback. Regardless, we are happy for the responses.

As measured by both oral feedback and the EOT survey, the course redesign has generally been successful. The toy project has been well received by students, faculty, and industry partners, based on oral feedback during and after terms, and feedback received during the symposium demonstration of students work. The instructors have found that the toy design project also serves as a vehicle to discuss aspects of design, communication, and professionalism, including topics that can be harder to tie in to a first year design project such as environmental and social impacts of engineering work, and equity considerations. As indicated in Figure 1, student responses to end-of-term survey questions indicate both the toy and demo projects were well received. Both helped with students' understanding of what mechanical engineering is, and students state they found the project to be engaging, and within their abilities, and that it felt like engineering work. Results are still positive, but less so, for if the project could help with their job search, if the project helped improve their confidence in design and their confidence if they're in the right program, and if the project helped with their journey as fledgling mechanical engineering students.

Interestingly, the demo design project trialed in 2020 was generally slightly better received by students. If one tallies the percentages of students selecting somewhat or strongly agree, $2 \%$ more agreed that the project was useful for their understanding, while $6 \%$ more agreed it was engaging. There was a $4 \%$ increase in those that agreed it was doable using their skills and the tools available, which is excellent given the challenges of the remote term. Unfortunately, 9\% fewer agreed the project could help them find a job. This may relate to the fact that the demo design project is less industrially relevant (since it was not connected to an industry visit from Spin Master or any other company). It may also relate to the general feeling of dismay among students trying to find their first work term during a pandemic, since the number of postings, interviews, and matches were all down compared to previous years. However, $4 \%$ more found the project helped improve their confidence in design, and 5\% more found it improved their confidence of if they were in the current program. Further, and most positively, $6 \%$ more found it helped them develop as engineers and $8 \%$ more agreed they felt like engineers while completing the work. It is likely that these increases, and the sample size, are both too low for these results to be statistically significant. The students involved were also different groups, and in very different circumstances. As such, any comparison between the projects should be made with caution. Regardless, we are happy that our pivot to a new project in response to the pandemic seems to have been as least as well received as the toy design project.

In addition to a good reception by students, the course instructors have observed that many students' projects demonstrate their efforts and success at learning engineering design and fabricating designs. A few projects illustrate unique and exceptional design and creativity. In contrast to this, the main challenge identified in both projects is in giving students suitable guidance at the start and throughout the project to ensure that all student teams have suitably scoped projects that are neither too ambitious, nor too simple. Over-scoped project are easier since students are usually (eventually) receptive to the idea that they should focus down to a more approachable problem. Under-scoped projects are more difficult to guide since students suggesting such projects seem to struggle with recognizing and performing the justified decision making necessary to actual design a toy, and or with exercising their creativity to find a challenging project that they are interested in. Many instead seem either disengaged or wish to focus on fabrication without considering the 'why' or 'how' questions that are hallmarks of engineering. Determining how to advise such students, and if/how more mathematical analysis might be brought into the course project are topics for further development.

We also observed, in 2020, that the nature of the project led to some confusion among students. Since the nature of the project was similar to a science fair or research project, many students believed the point of the project was to collect data, rather than to design a device which could demonstrate a concept (possibly while collecting data).While the idea of experimental apparatus design is of potential interest for the dual purpose of exposing students to design and research, it was not the focus of this project.

Considering the free-form comments on the EOT survey reinforces some of the above observed challenges. However, they also suggest other potential challenges/areas for improvement. 
In reinforcement, 5+ students in both 2017 and 2020 commented that they felt the project would have benefitted from clearer instructions of what the project was to entail and what types of projects were acceptable, including requests for the instructors to include lists of acceptable projects or of past projects. The course instructors have struggled with this request. As to the first part, we have felt that we have been clear, but are attempting to determine the root of this issue and address it. We are also aware that many students in $1 \mathrm{~A}$ are still coming to grips with the general open-endedness of University assignments. As to the second part, we have been resistant to generating lists of potential/past projects since we do not want to stifle student creativity, and do not want to encourage students to converge on the same projects/solutions. Indeed, on the occasions that we have mentioned past projects we have noted that many student groups gravitation toward variations on those projects. There is also the fact that the scope of a project is not entirely determined by it's topic, so a list of topics would likely be insufficient to ensure a suitable scope.

In addition to the challenges instructors have observed, in both 2017 and 2020 1-2 student wrote about feeling that the toy/demo project felt constrained compared to the project that 1A MTE students complete. As context, the 1A MTE student project is to build a robot using Lego Technix to perform the task of their choosing (e.g. sorting pills, playing an instrument, baking artistic pancakes, etc). Specifically, some students have said they felt constrained since they (thought they) weren't allowed to use electronics such as Arduino boards and sensors. We struggle with addressing this feedback. We have tried to communicate in the past that such equipment is both allowed and encouraged. We have also tried to communicate that the scope of (especially) 'design a toy' and (perhaps less so) 'design a demo' is as broad as students would like to make it. Most importantly, however, the 1A MTE students have a programming course that feeds into the Lego Robot project, while the ME students do not have this course until the second term. As such we feel we must leave the choice of whether to include electronic/programmatic components to the students.

Another 1-2 students have commented that the wide scope of the project disadvantages those who "aren't creative". While the course instructors disagree that creativity is solely an inherent trait, we do recognize that the creative challenge can be difficult. We are debating if there is a way to include an earlier exercise on creativity, or to create an 'ideas board' to allow for teams or individuals with a surplus of ideas to share them with those who have a deficit.

Finally, another 1-2 students in both years have commented that they wished the project involved more technical analysis. This is an idea that we have struggled with since the students do not have a deep background of knowledge/skills to draw from in their analysis, given that they are largely 18 years old with a Grade 12 education. We attempted to bring this analysis into the first design project in 2020, to have students analyze the design of their dynamometers. This idea holds promise, based on our initial observations, but will require refinement since the dynamometer project was only run for the first time in 2020.

In all, we feel the project is a success based on student numeric feedback. This is supported by the small number of negative comments and the fact that some of them are contradictory (that some find the project too constrained and some find it too open ended).

\section{Conclusions and Future Plans}

A first year mechanical engineering design course has been successfully revised to include an industrially relevant toy design project. This project has been well received by faculty, staff, and industry (as measured by oral feedback) and also by students (as measured by oral feedback and an end-of-term survey. Students have overwhelmingly agreed that the project is doable and engaging, and that it has increased their confidence and understanding of design and their engineering program. A pivot to a different project (designing high school physics demonstrations) ways piloted in Fall 2020 in response to the COVID-19 pandemic. Encouragingly, students rated the project similarly or more positively on nearly all metrics, except as to if the project would likely help them find a co-op job.

Challenges/questions in offering both projects remain: Can should the project begin earlier (to give more time for feedback/improvement in student work)? How can the best teambe formed and the best project ideas identified and pursued? How can the project aid the 'uncreative'? What is the right level of guidance to provide to students? Can we respond to student requests for more 'hard'/mathematical engineering analysis?

Given the good reception of the demo design project, the question remains open as to which project to offer in Fall 2021, especially if the University is (partially) open to in person classes. One option is to allow students to choose either project theme for their group (trying too offer the best of both worlds based on student preferences). The logistical and pedagogical challenges of offering this choice are still being considered.

\section{Acknowledgements}

The projects described in this paper, and the course itself, could not be offered without the support of the WEEF TAs and the First Year Engineering Office, including their academic and personal counsellors, and the Senior Tutors. The toy design project also could not have been run in the same way without the support of SpinMaster, and several volunteers from MME, WATiMake, and the IDEAs Clinic who volunteered their 
time for design critiques. We thank all of the above for their great efforts and the donation of their time and energies.

\section{References}

1) Michael Stachowsky and Andrew J B Milne, "What Makes a Good Assessment? Assessments for Learning", Proceedings of the Canadian Engineering Education Association, 2018, https://doi.org/10.24908/pceea.v0i0.13048.
2) MIT $2.00 \mathrm{~b}$ course page Available as of March 8 , 2021 from http://web.mit.edu/2.00b/www/index.html.

3) Carol Hulls, Chris Rennick, Sanjeev Bedi, Mary Robinson, and William Melek. "The Use of an OpenEnded Project to Improve the Student Experience in First Year Programming", Proceedings of the Canadian Engineering Education Association, 2015, https://doi.org/10.24908/pceea.v0i0.5737. 